CRORR 9 (2018), 25-35

\title{
Real Options in Irreversible Investment under Uncertainty: a Review
}

\author{
Esosa Enoyoze $^{1}$ and Sunday E. Omosigho ${ }^{2, *}$ \\ ${ }^{1}$ Edo University, Iyamho, Edo State, Nigeria \\ E-mail: < enoyoze.esosa@edouniversity.edu.ng> \\ ${ }^{2}$ University of Benin, Benin City, Nigeria \\ E-mail: <seomosigho@uniben.edu>
}

\begin{abstract}
The use of real options approach to determine the optimal time to execute irreversible investment under uncertainty has been studied extensively. Several relationships between uncertainty and irreversible investment has been proposed. We review the literature with the aim of answering the following questions: (i) What is the inadequacy in the methods used to solve the optimal timing problem in real options analysis for irreversible investment? (ii) What is the relationship between uncertainty and irreversible investment? (iii) How do you choose the stochastic process to incorporate in a real options analysis of an irreversible investment? Based on our study we clarify the apparent ambiguity in the relationship between uncertainty and irreversible investment and present four fundamental relationships between uncertainty and irreversible investment. Guidelines for selecting appropriate stochastic processes to include in an empirical study of an irreversible investment are suggested and some possible future directions of research are charted.
\end{abstract}

Keywords: irreversible investment, uncertainty, real options, stochastic process

Received: October 24, 2017; accepted: April 24, 2018; available online: July 24, 2018

DOI: $10.17535 /$ crorr.2018.0003

\section{Introduction}

The opportunity for irreversible investment abound in many countries. However, uncertainty surrounds the returns from such investments and so investors may wish to wait for some time before investing. This gives rise to the decision-making problem of determining the optimal time to execute an irreversible investment under uncertainty. There is a huge literature on this subject and there is apparent ambiguity on the relationship between irreversible investment and uncertainty. In this paper, we review papers on irreversible investment under uncertainty. We summarize the relationship between uncertainty and irreversible investment. Three issues

\footnotetext{
* Corresponding author.
} 
are addressed in this review: (i) What are the inadequacies in the methods used to solve the optimal timing problem in real options analysis for irreversible investment? (ii) What is the relationship between uncertainty and irreversible investment? (iii) How do you choose the stochastic process to incorporate in a real options analysis of an irreversible investment? Investment is defined as the act of incurring cost in a time interval $[0, \tau], \tau \geq 0$ with the expectation of rewards in future period $\mathrm{t} \geq \tau$. When $\tau=0$, we have instantaneous investment and when $\tau>0$, we have an investment which requires a type of installation of a device or construction process to be completed before reward or revenue can accrue to the investor. In some cases $\tau$ is a random variable. Naturally, investment is carried out in order to benefit from future revenue. However, future revenue is quite often a function of one or more variables in the economic system. When the levels of these variables are not known but they can be assigned some probability distribution, we say there is uncertainty. The simplest level of uncertainty is the binomial random variable, where a variable can take two values with probabilities $\mathrm{p}$ and $\mathrm{q}$ where $0<\mathrm{p}<1$ and $\mathrm{p}+\mathrm{q}=1$.

There is a broad spectrum of irreversible investment [1]. Mathematically, let $I$ be the cost of an investment. Suppose the investor changes his mind and decides to sell the investment. Let $B$ be the maximum amount an investor or a firm can realize from disposing the investment. If $B=0$ then the investment is completely irreversible or irreversible for short. If $I>B>0$, then the investment is partially irreversible or costly reversibility of investment [1]. In many irreversible investment situation, future rewards are uncertain and the option to postpone investment and obtain information becomes important. Indeed, if investment is irreversible, there is a return to waiting. Hence irreversibility and option to delay are important considerations to investors. Speight and Thompson [33] tested for time irreversibility in UK investment. They used the level of investment expenditure and groups in the manufacturing sector. The test results indicate that the irreversibility of investment patterns varies not only from industry to industry but also according to the type of capital being purchased, with significant time irreversibility detected in gross fixed capital formation and aggregate vehicles expenditure, and industrial sector groupings comprising fuels \& oil refining, engineering \& vehicles, and textiles \& leather. A firm will only invest if the value of an investment is at least equal to the value of waiting for further information or better investment opportunities to become available -the option value of waiting to invest later. Bulan [4] states that "if managers can wait for the resolution of uncertainty before deciding to pursue an irreversible investment, they can avoid potentially large losses by foregoing the investment altogether when the outcome is unfavorable."

Serven [32] presents a review of the real options literature to highlight the importance of uncertainty on the level of irreversible investment in Sub-Saharan Africa. Carruth et al. [5] provides a review of the literature on irreversible investment under uncertainty. They stated, "A general conclusion is that increased uncertainty, at both aggregate and disaggregate levels, leads to lower investment rates." This conclusion is very common in the literature but it is based on some pathological assumptions and gave rise to the idea that the relationship between irreversible investment and uncertainty is ambiguous [1]. Hence, we examine the established relationships between uncertainty and irreversible investment in this paper. In [39], a review of different areas of applications of real options theory is provided. Salvolainen [27] presents a 
review of the applications of real options in metal mining irreversible investments while the use of real options thinking in smart grids and energy systems is in [30].

In this paper, we review the literature on irreversible investment. Our review is restricted to the real options approach to irreversible investment under uncertainty. We provide a taxonomy of the relationship between uncertainty and irreversible investment. We shall consider methods for solving the optimal investment-timing problem and present research issues and challenges with these methods. We also consider how to select the stochastic process to be included in an empirical study of real options in irreversible investment. The choice of papers included in this review is influence by use of Science Direct, Google and the work of Webster and Watson [38]. An initial search provided thousands of papers but we used the questions answered in this review to focus on concepts to cover. Hence, we were able to reduce the number of papers available for review to those presented here.

The rest of the paper is arranged as follows. Section 2 presents a cursory review of fundamentals of the real options approach to irreversible investment. Various methods for obtaining solution to the investment-timing problem are in section 3. An ex-ray of the relationship between uncertainty and irreversible investment is presented in section 4 . Stochastic processes used in irreversible investment under uncertainty are in section 5. We highlight procedures for choosing stochastic processes used in real options analysis for irreversible investment. Conclusion is in section 6 .

\section{Real Options Theory for Irreversible Investment}

The real options approach to irreversible investment decision provides a sound mathematical framework for making optimal decision on irreversible investment whenever there is uncertainty over the future rewards from an irreversible investment. Consider an irreversible investment with a sunk cost $I$. Let $n \geq 1$ be a fixed integer. Let $X=\left(X_{1}, X_{2} \ldots, X_{n}\right)$, where $X_{i}, i=1,2, \ldots, n$ are random variables bearing on the irreversible investment decision process. Let the value of the project at time $t$ be $V(X, t)$ while the value of the option to invest is $F(X, t)=F\left(X_{1}, X_{2} \ldots, X_{n}, t\right)$. Let $\mathrm{T}$ be the optimal time of investment. The goal of the investor is to find $\mathrm{T}$ that maximizes the expected present value of the discounted return of the investment. The expected present value of the return of the investment is:

$$
V(X, 0)=E\left\{(V(X, T)-I) e^{-r T}\right\}
$$

where $r$ is the interest rate and $\mathrm{E}$ is the expectation operator. Real options theory states that the optimal time to invest is obtained by solving the constraint optimization problem

$$
F(X, t)=\sup E\left\{(V(X, t)-I) e^{-r t}\right\}
$$

subject to the boundary conditions and the stochastic process governing each of the random variable $X_{i}, i=1,2, \ldots, n$. The Bellman equation is $E(\mathrm{~d} F)=\mathrm{r} F \mathrm{dt}$.

The boundary conditions are designed to ensure that the optimal investment time, $\mathrm{T}$, is finite. Three crucial arguments [5] are generally used to derive the boundary conditions. These are based on when there is no investment, the payoff when the investment is optimal and the requirement that in the neighborhood of the optimal time for investment the function $F$ is 
smooth. In some cases, specific terminal values are specified. For example, in firms that are already in operation and are considering closure, terminal benefits to workers that will be laid off may be statutory.

\section{Methods for Solving the Optimal Timing Problem}

In the real options framework provided in section 2, analytic method is easily applied to obtain the optimal time to invest in a project when $n=1$. The analytic method when $n=1$ has been extensively discussed in the literature see e.g. $[5,27,38]$. When $n=2$, there are relatively few papers, see $[31,36]$. In this case, the resulting partial differential equation is restricted to the homogeneous situation in order to obtain analytic solution. The characterization provides the optimal investment trigger [37]. The optimal investment trigger is obtained by solving an ordinary differential equation using standard mathematical techniques. Quite often, to derive a problem having only one variable authors combine several sources of uncertainty into one. In [19] electricity price, production volume and support payment are combined into a single variable called operational gross margin. When the variables combined are correlated then the approach is reasonable.

In general, when $n=2$, we have a partial differential equation for the optimization problem to determine the optimal investment rule. Dixit and Pindyck [10] states that in general the two variables problem can be quite difficult to solve and that "the theory of partial differential equations has little to say about free boundary problems". They proposed that in special cases, the partial differential equation association with the optimal timing of irreversible investment when $n=2$ can be solved by reducing the partial differential equation to an ordinary differential equation using a ratio of the two random variables involved in the irreversible investment problem. This presupposes that the two variables can be collapsed into one [6] or they are correlated. In [26], the technique was used when price and quantity were considered in an irreversible investment decision.

Schmit et al. [31] used real options analysis with two stochastic variables to examine irreversible investment by ethanol firms. They noted that the associated second order partial differential equation has "no well-known solution". They used the approach suggest in [10]. Nunes and Pimentel [23] considered an investment problem with two sources of variation namely demand and investment cost which follow a jump-diffusion process. They reduced the resulting partial differential equation to an ordinary differential using the concept that the partial differential equation is homogeneous in the two variables. They noted that they could not find explicit solution to the original partial differential equation. Savolainen [29, p55] states that the partial differential equation approach can be quite complex when there are more than three stochastic variables.

The analytic solutions provided when $n \leq 2$ has been criticized on several grounds $[9$, 28]. First most empirical investment problems are affected by more than two variables. Secondly, only special stochastic processes such as geometric Brownian motion are incorporated. Samis et al. [28, p7] states, "A final aspect of modelling project uncertainty involves the relationship between the various uncertainties and also their interaction with the project and business environment. Some of these uncertainties may be independent of each 
other, such as metal concentration and metal price. Other project uncertainties may display some correlation, such as copper and gold prices." In cases where the sources of uncertainty are independent, it is not right to represent them by a single source of uncertainty. In such situations, the partial differential equation for the real options analysis is irreducible to an ordinary differential equation. For example, [9] used simulation based real options analysis when they were faced with multiple sources of analysis that were independent

Some authors, e.g. [5], argued that Monte Carlo simulation is more flexible than the analytic method of obtaining optimal investment rule because many issues avoided by the analytic method can be included in a simulation study. Zhu et al. [40] used simulation approach to examined irreversible investment in the oil industry involving uncertainty in oil price, investment cost, exchange rate, and investment environment. Ming et al. [22] also developed a simulation approach based on real options theory to study irreversible investment decision in the power generation process using more than one technology. Kitzing et al. [19] gave examples of authors that applied either the analytic approach or numerical method to obtain the optimal solution to a real option analysis for an irreversible problem. Schachter and Mancarella [30] examined critically the use of analytic methods, lattice technique and simulation techniques for obtaining optimal solutions in real options analysis of irreversible investment.

The discrete time approach is sometimes employed to circumvent the problems associated with finding the optimal timing of investment when there are multiple sources of uncertainty. The discrete time methods are often called lattice methods. The methods have been used in several areas [8]. Haahtela [15] provides a taxonomy of methods for obtaining solution in real options analysis for irreversible investment and then used cash flow simulation method in their analysis.

In view of the problems associated with using partial differential equations to solve investment problems with multiple sources of variations, it will be worthwhile to develop stable numerical methods for multi-variable problems. While there are cases where some variables are correlated, relying solely on correlations of variables might be unsuitable in some cases such as mining investments. Furthermore, for problems with short finite horizon, the use of discrete representations for the continuous stochastic processes is being considered. Partial differential equations associated with real options problem should be studied.

\section{Irreversible investment under uncertainty: Relationship and empirical results}

The early literature on irreversible investment under uncertainty based on real options analysis emphasized the optimal time to invest in a project. The analytic approach in continuous time used the geometric Brownian motion for a single underlying stochastic variable generating the uncertainty. This approach produced the celebrated result relating the time $\mathrm{T}$ to exercise the option to invest in an irreversible investment project to the level of uncertainty. A typical result given in [10, p142] states that the option to invest in an irreversible investment project should be exercise when $V(X, T)=\frac{\beta}{\beta-1} I$, where $\beta=\frac{1}{2}-\alpha / \sigma^{2}+\sqrt{\left(\alpha / \sigma^{2}-\frac{1}{2}\right)^{2}+2 r / \sigma^{2}}$. This result led to the conclusion that if uncertainty increases the investment trigger will also 
increase $[5,32,37]$. A typical statement of this result is: "there is a negative relationship between uncertainty and investment" [37]. This observation steered a series of both empirical and theoretical studies of the relationship between uncertainty and irreversible investment.

Several empirical studies illustrated the negative relationship between investment and uncertainty, see [21,32] and references therein. Svensson [34] used data from a survey in Uganda to demonstrate "that expectations of bad outcomes reduce both the probability that the firm will invest and the level of investment, while expectations of good outcomes have no significant effect." Darku [7] used data on Ugandan firms to illustrate a negative relationship between uncertainty and investment to deduce that uncertainty has a greater negative effect on investment for firms with partial reversible investment while uncertainty has a greater negative effect on investment level for firms with high degree of investment irreversibility.

In the empirical study of the relationship between uncertainty and investment, different proxy measures of uncertainty were used, [5, p130]. "The volatility of a firm's stock returns" was used in $[4,25]$ as a measure of uncertainty for a firm. [25] observed that competition could affect the negative relationship between uncertainty and investment. [17] measured competitive effect uncertainty by the price variance and concluded that both competition effect uncertainty and market size uncertainty influence the decision to invest. [13] used the Levy process to represent uncertainty in their model and derived an equation for the optimal investment boundary.

[18] states, "as uncertainty increases, real options theory tells us that the incentive to delay should grow stronger and the gap between the expected benefit and cost necessary to trigger investment should widen." Further, [18] used expected volatility of the future price of oil as a measure of uncertainty and concluded that when the expected volatility of the future price of oil increases, drilling activity decreases by a magnitude that aligns with the predicted real options model. Dunne and $\mathrm{Mu}$ [11], investigated the effect of uncertainty on the investment decisions of petroleum refineries in the U.S. They constructed uncertainty measures from the commodity futures market and used data on actual capacity changes to measure investment episodes. Since capacity changes in U.S. refineries occur infrequently, they investigated the investment process using hazard models. They also concluded that an increase in uncertainty decreases the probability that a refinery might adjust its capacity. Their findings lend support to theories that emphasize the role of irreversibility in investment decisions. In particular, as uncertainty in the refining margin rises, refiners delay their investment decisions.

Alvarez and Koskela [2] studied the impact of interest rate and revenue variability on the decision to carry out irreversible investment. They provided a mathematical characterization of the two-dimensional optimal stopping problem and showed that interest rate variability has either a decelerating or accelerating impact on investment depending on whether the current interest rate is below or above the long-run steady state value. They concluded that increased revenue volatility strengthens the negative impact of interest rate volatility and vice versa.

However, some other sources indicate that the negative relationship between investment and uncertainty is not generally correct. Such studies employed a redefinition of the underlying stochastic processes that impinge on the value of the investment. The probability of investing 
when there is increasing uncertainty was introduced to give insight to the effect of uncertainty on investment. Sarkar [29] illustrates that "an increase in uncertainty can actually increase the probability of investing and thereby have a positive impact on investment" This claim that uncertainty can have a positive impact on investment has been subjected to further scrutiny. [37] considered several stochastic processes used in irreversible investment analysis and stated "... increase uncertainty, in certain situations, may actually encourage investment due to a higher probability of investing." Sarkar [29] also recognized this positive effect of increasing variance on investment, which they attributed to realization effect. [16] used oil price volatility to examine the effect of uncertainty on investment and concluded that a $\mathrm{U}$ shaped relationship exists between uncertain and investment. Binding and Dibiasi [3] considered the effect of exchange rate uncertainty on investment. They concluded "that uncertainty negatively affects investment in equipment and machinery through real-option effects and believe that uncertainty positively influences expenditures in research and development through growthoption effects"

From the foregoing discussion on the relationships between uncertainty and investment, we infer the following four propositions:

Proposition 1. (Dixit and Pindyck [10])

Increasing Uncertainty has a negative effect on investment.

Proposition 2. (Henriques and Sadosrky [16])

There is a $U$ shaped relationship between uncertainty and investment.

Proposition 3. (Sarkar [29]; Wang and Driver [37])

Increased uncertainty has a variance effect and a realization effect on investment.

Proposition 4. (Sarkar [29]; Wang and Driver [37])

Increasing Uncertainty has a positive effect on investment due to a higher probability of investing.

It is worth noting that each of these propositions have been established under peculiar scenario. Indeed, on the relationship between uncertainty and investment, different authors have often used different stochastic variables in their studies. Some of these stochastic variables include exchange rate, (real wages, material prices, output prices), demand, share return, market share, sales growth rate, and energy price [16]. These variables are hardly combined in a single study. One can infer that there is no single proposition on the relationship between increasing uncertainty and irreversible investment. Indeed [20] illustrated that when several stochastic variables are involved in the investment process, the effect of "increased uncertainty" can be positive or negative for different firms even in the same industry. For example, [20] stated, "For demand uncertainty, mining firms with long establishment years and those with medium to large firm size are prone to investment under high uncertainty, implying that under high demand uncertainty large firms have more resources (capital) to commit investment. However, 
for other uncertainties, especially for small mining firms, more investment is undertaking under low uncertainty than high uncertainty."

The four propositions show that there is no single relationship between uncertainty and irreversible investment. Specific and unambiguous axioms give rise to one of the relationship in the propositions. This observation points to the need for a careful study to identify the state variables and associated stochastic processes in an empirical study of an irreversible investment project. In theoretical work, authors specify the stochastic processes that they are interested in using. We advocate further studies of irreversible investment process involving several stochastic variables simultaneously.

\section{Choice of Stochastic processes for real options analysis}

Schachter and Mancarella [30, p267] stated that "the use of stochastic process is an issue since there is no clear way of representing some uncertainties like demand." Ozorio et al. [24] examined the issue of how to select an appropriate stochastic process including parameters of the stochastic process used in real options valuation. The selection process entails analyzing time series data using maximum likelihood method and appropriate information criteria. In practice, the first step is to identify the variables that should be included in the analysis. The issue of using a single variable or multiple variables must also be decided. The need to use appropriate stochastic process was also the concern of [38] who investigated the relationship between uncertainty and investment under various stochastic processes. They demonstrated that different stochastic processes can give rise to different invest rule and the relationship between uncertainty and investment. Ewald and Wang [12] illustrated that the choice of stochastic process can be important by comparing the effect of using a Cox-Ingerson-Ross process with using the geometric mean reversion process. The choice of stochastic process to use for irreversible investment analysis is dictated by the underlying state variable. Some consider demand and investment costs, [23]; construction cost and revenues [35]; price of output, [36]; profit, [34]; and so on. That the choice of stochastic process for the state variable is important was earlier identified by Gutierrez [14]. Where alternative stochastic processes can be applied to a state variable, we propose that the effects of the various stochastic processes should be examined to have robust information for decision-making. This may require the applications of several solution techniques, some of which may not be analytically tractable.

\section{Conclusion}

We have examined generalized inference between uncertainty and irreversible investment in one direction and pointed out that there are four plausible relationships between increasing uncertainty and irreversible investment. Simulation and its variants, such as Monte Carlo simulation and least square simulation, and lattice method are used in real options analysis in many practical situations. This is because in practical situations with multiple sources of uncertainty, closed form solutions are not available. In fact, mathematical methods for solving partial differential equations associated with such systems are not available. Therefore, efforts should be directed at developing mathematical methods for solving partial differential 
equations associated with irreversible investment problems with multiple sources of uncertainty that are independent. When the multiple sources of uncertainty are correlated, then the sources of uncertainty can be redefined into one stochastic variable. The associated partial differential equation is reducible to ordinary differential equations with standard method for obtaining solutions. However, in situation where the multiple sources of variations are independent the optimal timing problems gives rise to partial differential equations that are irreducible to ordinary differential equations.

\section{References}

[1] Abel, A. B., Dixit, A. K., Eberly, J. C. and Pindyck, R. S. (1996). Options, the value of capital, and investment. The Quarterly Journal of Economics, 111(3), 753-777.

[2] Alvarez, L. H. R. and Koskela, E. (2006). Irreversible investment under interest rate variability: some generalizations. The Journal of Business, 79(2), 623-644.

[3] Binding, G. and Dibiasi, A. (2017). Exchange rate uncertainty and firm investment plans evidence from Swiss survey data. Journal of Macroeconomics, 51, 1-27.

[4] Bulan, L. T. (2005). Real options, irreversible investment and firm uncertainty: new evidence from U.S. firms. Review of Financial Economics, 14, 255-279. doi:10.1016/j.rfe.2004.09.002

[5] Carruth, A. Dickerson, A. and Henley, A. (2000). What do we know about investment under uncertainty? Journal of Economic Surveys, 14(2), 119-154. doi:10.1111/14676419.00107

[6] Cortazar, G., Schwartz, E. S. and Casassus, J. (2001). Optimal exploration investments under price and geological-technical uncertainty: a real options model. R\&D Management, 31(2), 181-189.

[7] Darku, A. B. (2001). Private investment, uncertainty, and irreversibility in Uganda. The African Finance Journal, 3(1), 1-25.

[8] Dehghani, H, Ataee-Pour, M., Esfahanipour, A. (2014). Evaluation of the mining projects under economic uncertainties using multidimensional binomial tree. Resources Policy, 39, 124-133.

[9] Dimitrakopoulos, R. G. and Sabour, S. A. A. (2007). Evaluating mine plans under uncertainty: can the real options make a difference? Resources Policy, 32, 116-125.

[10] Dixit, A. K. and Pindyck, R. S. (1994). Investment under uncertainty. Princeton New Jersey: Princeton University Press.

[11] Dunne, T. and Mu, X. (2010). Investment spikes and uncertainty in the petroleum refining industry. Journal of Industrial Economics, 58(1), 190-213.

[12] Ewald, C.-O. and Wang, W.-K. (2010). Irreversible investment with Cox-Ingersoll-Ross type mean reversion. Mathematical Social Sciences, 59(3), 314-318. doi.org/10.1016/j.mathsocsci.2009.12.002.

[13] Ferrari, G. and Salminen, P. (2016). Irreversible investment under Levy uncertainty: an equation for the optimal boundary. Advances in Applied Probabillity, 48(1), 298-314.

[14] Gutierrez, O. (2005). Real options and the Jorgensonian user cost of capital. Investigaciones Economica, 29(3), 625-630. 
[15] Haahtela, T. (2010). Cash flow simulation embedded real options. Lecture Notes in Management Science (2010) 2, Proceedings of the $2^{\text {nd }}$ International Conference on Applied Operational Research, 418-430. http://orlabanalytics.ca/lnms/archive/v2/lnmsv2p418.pdf [Accessed 24/10/2017]

[16] Henriques, I. and Sadorsky, P. (2011). The effect of oil price volatility on strategic investment. Energy Economics, 33, 79-87. doi.org/10.1016/j.eneco.2010.09.001

[17] Jouvet, P.-A., Cadre, E. L. and Orset, C. (2011). Irreversible investment, uncertainty and ambiguity: The Case of the Bioenergy Sector. Working Paper 2011-01. http://www.agfoodtrade.eu [Accessed 24/10/2017]

[18] Kellogg, R. (2014). The effect of uncertainty on investment: Evidence from Texas oil drilling. American Economic Review, 104(6), 1698-1734.

[19] Kitzing, L., Juul, N., Drud, M. and Boomsma, T. K. (2017). A real options approach to analyse wind energy investments under different support schemes. Applied Energy 188, 8396. doi.org/10.1016/j.apenergy.2016.11.104.

[20] Ma, Y. (2015). Uncertainty and investment: evidence from the Australian mining industry. Resources Policy, 46, 191-201.

[21] Menashe, Y. (2005). Is the firm-level relationship between uncertainty and irreversible investment non-linear? http://www.boi.org.il/deptdata/mehkar/papers/dp0512e.pdf [Accessed 24/10/2017]

[22] Ming, Z, Ping, Z., Shunkun, Y. and Ge, Z. (2016). Decision-making model of generation technology under uncertainty based on real option theory. Energy Conversion and Management, 110, 59-66.

[23] Nunes, C., and Pimentel, R. (2017). Analytical solution for an investment problem under uncertainties with shocks. European Journal of Operational Research, 259, 1054-1063.

[24] Ozorio, L. de M., Bastian-Pinto, C. de L. and Brandão, L. E. T. (2012). The choice of stochastic process in real option valuation.

http://realoptions.org/openconf2012/data/papers/49.pdf [Accessed 3/6/2017]

[25] Patnaik, R. (2015). Competition and the real effects of uncertainty. https://pdfs.semanticscholar.org/6cef/99f5d97106b7803d5352916fc1b945740d59.pdf [Accessed 24/10/2017]

[26] Paxson, D. and Pinto, H. (2005). Rivalry under price and quantity uncertainty. Review of Financial Economics, 14, 209-224.

[27] Savolainen, J. (2016). Real options in metal mining project valuation: Review of literature. Resources Policy 50, 49-65. doi.org/10.1016/j.resourpol.2016.08.007.

[28] Samis, M., Martinez, L., Davis, G. A., and Whyte, J. B. (2012). Using Dynamic DCF and Real Option Methods for Economic Analysis in NI43-101. Technical Reports. http://inside.mines.edu/ gdavis/Papers/ValMin.pdf [Accessed 24/10/2017]

[29] Sarkar, S. (2000). On the investment-uncertainty relationship in a real options model. Journal of Economic Dynamics \& Control, 24, 219-225.

[30] Schachter, J. A. and Mancarella, P. A. (2016). A critical review of real options thinking for valuing investment flexibility in Smart Grids and low carbon energy systems. Renewable and Sustainable Energy Reviews 56, 261-271. doi.org/10.1016/j.rser.2015.11.071 
[31] Schmit, T. M., Luo, J. and Conrad, J. M. (2011). Estimating the influence of U.S. ethanol policy on plant investment decisions: A real options analysis with two stochastic variables. Energy Economics, 33(6), 1194-1205.

[32] Serven, L. (1997). Uncertainty, instability and irreversible investment. Policy Research Working Paper No 1722. The World Bank.

[33] Speight, A. and Thompson, P. (2006). Is Investment Time Irreversible? Some empirical evidence for disaggregated UK Manufacturing Data. Applied Economics, 38 (19), 22652275 .

[34] Svensson, J. (2000). Is the bad news principle for real? Economics Letters, 66, 327-331.

[35] Thijssen, J. J. J. (2015). A model of Irreversible Investment with construction and revenue uncertainty. Journal of Economic Dynamics and Control, 57, 250-266.

[36] van den Goorberg, R. W. J., Husismsn, K. J. M. and Kort, P. M. (2003). Risk aversion, price uncertainty and irreversible investment (Center Discussion Paper, Vol 2003-19). Tilburg: Finance

[37] Wang, G. Y. and Driver, C. (2015). The relationship between uncertainty and investment under various Stochastic Process. http://www.academia.edu/22683993 [Accessed $24 / 10 / 2017]$

[38] Webster, J. and Watson, R. T. (2002). Analyzing the past to prepare for the future: Writing a literature Review. MIS Quarterly, 26(2), 12-22.

[39] Zeng, S. and Zhang, S. (2011). Real Options literature review. iBusiness, 3, 43-48. doi:10.4236/ib.2011.31007

[40] Zhu, L., Zhang, Z., and Fan, Y. (2015). Overseas oil investment projects under uncertainty: How to make informed decisions? Journal of Policy Modeling, 37(5), 742-762. doi.org/10.1016/j.jpolmod.2015.08.001 S0161893815000800 